\title{
HISTÓRIA
}

DAS CIÊNCIAS

E EDUCAÇÃO

\section{As formas de pensar a vida como objeto de estudo primordial da biologia}

\section{The ways of thinking about life as an object of primordial biology study}

\author{
Márcia Mendes Simão| Secretaria de Educação de Goiás \\ Rones de Deus Paranhos | Universidade Federal de Goiás \\ Simone Sendin Moreira Guimarães | Universidade Federal de Goiás \\ sisendin@ufg.br \\ https://orcid.org/0000-0002-6559-2591
}

RESUMO A constituição da biologia enquanto ciência autônoma, com um corpo de ideias que se apartam da tutela prioritária de características físicas e químicas, se apresenta como um processo em que coexistem diferentes percepções do objeto vida. Este artigo tem como objetivo discutir a dinâmica desse objeto a partir da epistemologia de Ludwig Fleck (1896-1961) ao considerar que as construções epistemológicas do fenômeno vida podem ser reconhecidas no desenvolvimento do pensamento biológico como "estilos de pensamento biológico". O Estilo de Pensamento determina as ideias que serão desenvolvidas dentro de um Coletivo de Pensamento, pois é o estilo que direciona a reelaboração dessas ideias. Sendo assim, o conceito de vida foi direcionado pelo estilo de pensamento biológico dominante em cada período histórico e colaborou para o pensamento biológico atual. A partir desse entendimento, é possível utilizar a construção do conceito de vida como uma valiosa estratégia para compreender o passado, segundo nossa visão de mundo, e o presente, mediante visões de mundo que contribuíram para o desenvolvimento do pensamento biológico.

Palavras-chave filosofia da biologia - Ludwig Fleck (1896-1961) - estilos de pensamento.

ABSTRACT The constitution of biology as an autonomous science, with a body of ideas that depart from the priority protection of physical and chemical characteristics, presents itself as a process in which different perceptions of the life object coexist. This article aims to discuss the dynamics of this 
object from the epistemology of Ludwig Fleck (1896-1961), when considering that the epistemological constructions of the life phenomenon, can be recognized in the development of biological thinking as "styles of biological thought". The Thinking Style determines the ideas that will be developed within a Thinking Collective, as it is the style that directs the re-elaboration of these ideas. Thus, the concept of life was guided by the dominant biological thinking style, in each historical period, and contributed to the current biological thinking. Based on this understanding, it is possible to use the construction of the concept of life as a valuable strategy to understand the past, according to our worldview, and the present, through worldviews that contributed to the development of biological thinking.

Keywords philosophy of biology - Ludwig Fleck (1896-1961) - thinking styles.

\title{
Introdução ${ }^{1}$
}

A biologia, como outras áreas de estudo, apresenta influências históricas, sociais e culturais na formulação da sua base conceitual. A constituição da biologia enquanto ciência autônoma, isto é, com um corpo de ideias que se aparta da tutela prioritária de características físicas e químicas, se apresenta como um processo em que coexistem diferentes percepções do objeto vida.

Essas percepções estão relacionadas aos modelos explicativos para os eventos biológicos, representam o contraste das visões de mundo (ontologia) sobre o fenômeno vida e podem ser interpretadas como diferentes estilos de pensamento, que figuram também no ensino de conhecimentos biológicos. O (re)conhecimento dessas influências tem implicações na delimitação e formas de compreensão do objeto da biologia e nas possibilidades de ensino de conhecimentos biológicos.

\section{A delimitação das ciências da vida}

A construção do conhecimento científico não é diferente de qualquer outra atividade coletiva e social e pode ser influenciada, com diferentes finalidades, por outras esferas menos especializadas da sociedade (Fleck, 2010). Por isso, o entendimento do desenvolvimento do pensamento biológico requer uma viagem ao contexto intelectual da Grécia Antiga (século VII a V a.C.),

\begin{abstract}
[...] principalmente a partir do século VI antes da Era Cristã, pois foi quando se iniciou e se desenvolveu, pela primeira vez, o espírito científico, marco fundamental na evolução do pensamento humano, e quando ocorreria, em consequência, o advento da ciência abstrata. Esse novo espírito viria a ser o grande divisor entre a civilização grega e as demais civilizações daquele período histórico, que trilhariam caminhos distintos na busca de respostas às inquietações do homem quanto a seu destino e quanto à natureza e seus fenômenos (Rosa, 2012, p. 99).
\end{abstract}

O reconhecimento de imbricações histórico-sociais reflete no entendimento dos fenômenos a partir da apropriação da natureza pelo ser humano. Como ponto de partida para o

1 Este artigo é parte da dissertação de mestrado da primeira autora, e neste recorte pretende colaborar para o entendimento do processo de construção da área de estudo da vida, considerando uma visão integrada dos conceitos biológicos, em especial considerando as ideias de Ludwig Fleck. Ver: Simão (2018). 
entendimento da formação do pensamento ocidental, temos o reconhecimento das influências da filosofia grega em tal construção, pois a visão de mundo e universo do filósofo grego Aristóteles "acabou por imperar no mundo ocidental por quase vinte séculos" (Andery et al., 2000, p. 88).

Nesse cenário, as explicações mitológicas passam a ser deixadas em segundo plano ao ponto de os pensadores da Escola de Mileto proporem a compreensão do mundo a partir da observação da natureza (Andery et al., 2000). Em outras palavras, o pensamento mitológico perde a primazia na busca deexplicações para os fenômenos e ascende uma nova possibilidade, um prenúncio da racionalidade.

Segundo Andery et al. (2000), os pensadores da Escola de Mileto desenvolveram formas de observação e explicação diferentes para os fenômenos da natureza. Segundo Lopes (1991), Tales de Mileto foi o primeiro a propor a existência de um elemento fundamental, de uma substância primordial. Segundo ele, todas as coisas seriam feitas de água.

\begin{abstract}
Já Anaximandro,outro filósofo da Escola de Mileto, afirmava que a substância primordial de todas as coisas não é a água, nem, efetivamente, nenhum outro corpo material conhecido. Para ele, o elemento fundamental de todas as coisas é infinito e eterno e está subjacente em todos os mundos. Essa substância se transforma em objetos materiais que nós percebemos. Segundo Anaximandro, no mundo material existe uma proporção definida de ar, de fogo, de água e de terra. A competição entre esses elementos concebidos como deuses, ou seja, a proporção de tais elementos, é regulamentada por uma fatalidade, por uma certa necessidade - necessidade de proporção entre esses elementos - que constituiria, segundo certos filósofos, a origem da noção da lei da natureza. Para Anaxímenes, terceiro pensador da Escola de Mileto, a substância primordial é o ar. A alma do homem é feita de ar, o fogo é o ar rarefeito; ao condensar, o ar se transforma em água que, por sua vez, se condensa em terra, em pedras, a origem da noção (Lopes, 1991, p. 95-96).
\end{abstract}

Entre os que pertencem a essa escola de pensamento, considerando essas ideias como fruto de um coletivo (Fleck, 2010), a explicação sobre a origem do universo e dos fenômenos da natureza estava direcionada a elementos diferentes, mas relacionava-se à natureza. Apesar de marcar o início de desvinculação do pensamento mitológico, nota-se que os aspectos religiosos moldavam o pensamento filosófico da época ao considerar o interesse pela origem da alma.

Como resultado desse olhar direcionado à compreensão da natureza, mesmo antes da demarcação de uma área de estudo e do uso de um termo específico, já no período clássico (século V e VI a. C.), temos a contribuição de filósofos gregos na elaboração de ideias sobre a vida (Andery et al., 2000). Nesse período, Platão argumentava que os seres viventes eram dotados de uma alma, que Ihes conferia o atributo vida (Oparin, 1989). Esta ideia foi reelaborada por Aristóteles, outro filósofo grego e discípulo de Platão, que entendia que os seres vivos eram formados pela "causa eficiente", alma; e "causa material", a matéria (Aristóteles, 2010). Partindo desses princípios, ele considerava que a alma se apoderava da matéria, corpo, atribuindo-lhe uma essência capaz de vivificar. Aristóteles, no tratado Da alma, utiliza o termo "alma" com o significado de "vida" e ainda indica a presença desse princípio a partir de características que denomina faculdades, como "o entendimento, a sensibilidade, o movimento de deslocação e o repouso, e ainda o movimento relativo à nutrição, o envelhecimento e o crescimento" (Aristóteles, $2010 a$, p. 64). Contudo, o autor explica que não se pode conceber um só tipo de alma, devido à presença ou ausência de faculdades em determinados seres. Desse modo, ao classificar os 
As formas de pensar a vida como objeto de estudo primordial da biologia

seres pela complexidade de sua alma, relaciona a vida à caracterização de cada ser analisado (Andery et al., 2000). Sobre esses diferentes tipos de alma, ou vida, Coutinho (2005) afirma que

Aristóteles realiza uma tripartição da alma, considerando a alma vegetativa, característica dos vegetais, que seria responsável pelas faculdades de nutrição e reprodução; a alma sensitiva, característica dos animais, que traria consigo as faculdades da locomoção e da sensibilidade; e, finalmente, a alma intelectiva, característica do ser humano, que também possui a faculdade da razão (Coutinho, 2005, p. 51).

Nas argumentações desse pensador, percebe-se o contato com a circulação das ideias entre os filósofos gregos, que proporcionou o desenvolvimento do conceito de alma apresentado por Aristóteles. Porém, o diferencial de Aristóteles está em relacioná-la aos fenômenos mais profundos dos seres vivos. Isso colabora para a compreensão da construção do conceito de vida entre os filósofos gregos e ajuda a compreender os reflexos dessas ideias nas concepções que vigoraram, principalmente, na filosofia ocidental. Sobre esse tema, Andery et al. (2000, p. 88) assinalam que o "mundo e o universo, da maneira como Aristóteles os via, e que acabou por imperar no mundo ocidental por quase vinte séculos, eram finitos, hierarquizados, governados pela finalidade e neles imperavam as diferenças qualitativas".

Para Alfonso-Goldfarb (1994), na Idade Média (séc. V ao XV), a Europa experimenta a cristianização e propagação do pensamento aristotélico. Oparin (1989) esclarece que esse período acrescentou pouco às discussões científicas porque estas estavam moldadas por uma filosofia teológica. $\mathrm{O}$ autor acrescenta que os expoentes da Igreja receberam essas ideias, inicialmente, como contrárias aos modos explicativos divinos de criação do mundo vivo, mas houve uma conciliação quando perceberam que os pressupostos de Aristóteles poderiam colaborar para a consolidação da cultura cristã. Assim, a teoria da geração espontânea foi reelaborada por filósofos como Tomás de Aquino, para validar a ideia da ação do espírito divino na matéria inerte, citada no livro de Gênesis. Apesar das contribuições das ideias de Aristóteles para as pesquisas sobre o mundo vivo, as potencialidades dessa abordagem não foram suficientemente exploradas até o século XVI (Mayr, 2008). De acordo com Andery et al. (2000), nesse período, a construção do pensamento científico sofria uma grande limitação do espírito religioso, resultado do intenso controle da Igreja sobre a produção e veiculação do conhecimento. Segundo Mare (2002), as distorções das ideias de Aristóteles ilustram bem a visão de mundo determinada, na Idade Média, pela relação Deus/ homem. Para o autor, os mil anos de doutrinamento religioso refrearam o desenvolvimento do pensamento científico, porém também apresentaram reflexos de uma resistência racionalista que culmina no delinear de uma perspectiva estruturada na relação homem/natureza.

Nesse novo olhar, o desenvolvimento do pensamento biológico experimentou, entre o século XVIII e início do século XIX, segundo Mayr (2008), as contribuições da fisiologia, taxonomia e embriologia. Até então, essas áreas compunham a chamada história natural, definida por Foucault (2000, p. 101) como a "ciência dos caracteres que articulam a continuidade da natureza e sua imbricação". No entanto, o autor deixa claro que era um campo destinado ao estudo dos seres vivos e, juntamente com as escolas de medicina, entre o século XVII e o XVIII, tais áreas foram responsáveis por grandes contribuições para o estudo do mundo vivo.

Segundo Mayr (1998), um nome que ganhou um grande prestígio nesse período é o do naturalista Carl von Linné (1707-1778) ou Lineu. As influências de sua crença religiosa repercutiram em um direcionamento à teologia natural, centrada no estudo da natureza a partir 
de existência de uma ordem e de uma estabilidade divina (Mare, 2002). Lineu tinha como características de sua personalidade o rigor e a capacidade de organização, pontos-chave para a elaboração de um sistema de classificação binomial que favoreceu o desenvolvimento de pesquisas relacionadas a classificação dos seres vivos (Mayr, 1998).

Contrapondo-se à visão de fixismo extremo atribuída a esse naturalista, Canguilhem (2012, p.43) esclarece que "Lineu nunca abandonou completamente a ideia de algumas ordens naturais criadas por Deus, mas reconheceu a existência de espécies, e até mesmo de gêneros filhos do tempo". O reconhecimento da possibilidade da existência de processo de diversificação dos seres vivos, ao longo do tempo, faz com que ele seja apontado como um dos precursores da ideia de transformismo, conceito estruturante da teoria da evolução (Mare, 2002).

A intervenção da filosofia cristã no estudo do mundo vivo não é o único obstáculo para o desenvolvimento desse campo, pois, a partir do século XVII, com o direcionamento das leis físicas, a maneira de conhecer e de racionalizar o mundo vivo enfrentou um distanciamento das particularidades desse fenômeno (Foucault, 2000). Assim, a originalidade e as especificidades do fenômeno vida foram entendidas como pontos determinantes para uma abordagem diferenciada, colaborando para a delimitação e desenvolvimento de um campo específico (Canguilhem, 2012).

Tanto a filosofia cristã quanto leis físicas pautavam-se na concepção fixista, mas a manifestação da variabilidade na diversidade de seres vivos, reforçada pelas grandes navegações no fim da Idade Média, é um fenômeno que não se adequa a nenhuma dessas visões e possibilitou as discussões sobre a necessidade de uma abordagem distintapara os fenômenos do mundo vivo (Mayr, 1998). Esse processo de racionalização alicerçou um pensamento científico a serviço de um processo produtivo, impulsionado pela modificação da natureza (Andery et al., 2000), assim, assumiu uma perspectiva que se distanciava das peculiaridades do estudo da vida. No entanto, não podemos desprezar as contribuições desse modelo de pensamento, pois a visão sistemática na interpretação do fenômeno vida conta com conceitos analíticos propiciados por metodologias analítico-explicativas, uma característica dos pressupostos mecanicistas.

Pode-se, então, dizer que o termo biologia é apresentado ao cenário científico por JeanBaptiste Pierre Antoine de Monet, chevalierde Lamarck (1744-1829) e Gottfried Reinhold Treviranus (1776-1837), no início século XIX (Canguilhem, 2009), com a proposta de delimitação de uma área exclusiva para estudo da vida, em busca da autonomia em relação aos conceitos do mundo vivo (Foucault, 2000).

Entretanto, a emancipação desse campo de estudo tem como marco a possibilidade de uma visão sistêmica dos conhecimentos biológicos já produzidos, materializada na proposta de um modelo cognoscível para a problemática da diversidade do mundo vivente. A perspectiva evolutiva, proposta pelo inglês Charles Robert Darwin (1809-1882) em 1859, alcançou um destaque especial ao demonstrar que:

[...] provas abundantes provenientes da anatomia comparativa, da embriologia, do comportamento, da agricultura, da paleontologia e da distribuição geográfica dos organismos. Desde aquela época, todas as muitas milhares de observações feitas em cada uma dessas áreas reforçaram a essência da hipótese de Darwin. A essas observações foram acrescentadas abundantes provas com que Darwin nem poderia ter sonhado, oriundas especialmente da paleontologia e da biologia molecular. O acúmulo de um século de tais provas estabelece a descendência, com modificações, de ancestrais comuns como um fato científico (Futuyma, 2002b, p. 66). 
O florescimento do pensamento evolutivo, com os fundamentos da genética clássica e moderna, contribui para a autonomia da biologia (Mayr, 1998). O pensamento evolutivo trouxe uma explicação para a diversidade das espécies, que se contrapunha às ideias de fixidez ordenada, visão que vigorava até então no mundo ocidental. No entanto, devemos perceber que o desenvolvimento dessa nova forma de enxergar o mundo vivo retrata a reelaboração de ideias preexistentes sobre a diversidade das espécies e tem seu ponto de inserção científica na ideia de seleção natural, pois é a partir dessa reconstrução que "Darwin e Wallace transformaram a especulação em teoria científica" (Futuyma, 2002a, p.16). Então, as ideias sobre seleção natural, fortalecidas pelos princípios explicativos da genética clássica e moderna, favoreceram o delineamento da biologia evolutiva, ponto-chave para a emancipação da biologia. Portanto, a área de estudo da vida é relativamente nova, mas a interpretação dos fenômenos vitais, como a formulação de outros conceitos científicos, sofre influências de modelos interpretativos que direcionam as ideias em dado momento histórico. As concepções que deixaram marcas no desenvolvimento do pensamento biológico, por representarem um papel importante na (re) construção do objeto de estudo da biologia, são as ideias vitalistas e mecanicistas, opostas entre si e superadas pela visão organicista (Mayr, 2008).

\section{O mundo vivo sob dois olhares controversos}

Os pressupostos teóricos e epistemológicos do paradigma dominante, em determinado momento histórico, de um modo ou de outro, predominam na elaboração conceitual de cada área do conhecimento (Fleck, 2010). Contudo, não se pode desconsiderar que outras linhas de pensamento coexistiam no mesmo período (Mayr, 1998), circunstância que impossibilita uma visão linear da história da ciência.

Segundo Capra e Luisi (2014), os séculos XVI e XVII são marcados pela ressignificação da compreensão de mundo, a partir do processo de divisão da filosofia e a estruturação da filosofia natural, considerada precursora das ciências naturais. Os autores referem-se ao desenvolvimento de conhecimentos que estruturaram diferentes visões dos fenômenos naturais. Entre os conhecimentos elaborados nesse período estão os pilares da perspectiva mecanicista, que reestruturaram a abordagem dos fatos científicos ao refutar as explicações sobrenaturais (Mayr, 2008). Para Santos (2008, p. 30),

\footnotetext{
[...] na visão da mecânica newtoniana, o mundo da matéria é uma máquina cujas operações se podem determinar exatamente por meio de leis físicas e matemáticas, um espaço vazio, um mundo que o racionalismo cartesiano torna cognoscível por via da sua decomposição nos elementos que o constituem. Esta ideia do mundo-máquina é de tal modo poderosa que se vai transformar na grande hipótese universal da época moderna, o mecanicismo.
}

A maior visibilidade dos aspectos quantitativos e a desvalorização dos aspectos qualitativos é um dos resultados dessa modificação, que ocorre por meio de uma releitura dos fenômenos. Nesse sentido, a física, alicerçada na matemática, passa a ser revelação do mundo real na compreensão dos chamados fisicalistas (Mayr, 2008).

Os adeptos dessa corrente de pensamento defendiam que os seres vivos também poderiam ser estudados pelos mesmos princípios com os quais são estudados os fenômenos físicos, 
mas, no que concerne ao mundo vivo, a superficialidade de comparação entre um organismo e uma máquina gerou divergências entre físicos e biólogos (Mayr, 2008). As tensões entre visão mecanicista e visão integrada se estruturavam nas particularidades desse objeto de estudo. Nesse sentido, Canguilhem $(2012$, p. 5) argumenta que a racionalidade "só pode aplicar-se à vida reconhecendo a originalidade da vida".

Entre o século XVII e XIX, as especificidades do fenômeno vida ampararam correntes de pensamento diferentes, entre elas, a concepção vitalista, que defendia a ideia de que os fenômenos relativos aos seres vivos (evolução, reprodução e desenvolvimento) seriam controlados por um impulso vital de natureza abstrata, que complementaria as forças físicas ou as interações fisioquímicas conhecidas (Capra; Luisi, 2014). Assim, a visão do todo seria a partir da ideia da força vital, que se assemelha à ideia de alma de Aristóteles.

A ideia de força vital, Lebenskraft em alemão, recebe muitas críticas e tem seu declínio explicado, em primeiro lugar, pelo

\footnotetext{
[...] fracasso de literalmente milhares de experimentos realizados para mostrar a existência de uma Lebenskraft; em segundo lugar, a constatação de que a nova biologia, com os métodos da genética e da biologia molecular era capaz de resolver todos os problemas para os quais cientistas tradicionalmente haviam invocado a Lebenskraft. Em outras palavras, a proposta de uma Lebenskraft havia se tornado desnecessária (Mayr, 2005, p.38).
}

Como exemplo desses procedimentos, temos, nos séculos XIX e XX, a síntese, em condições experimentais, de diversas substâncias orgânicas, que colaborou para a superação do pressuposto vitalista de que as substâncias orgânicas só poderiam ser produzidas por sistemas vivos (Oparim, 1989). Entre elas está a ureia, composto orgânico presente na urina e no suor de animais, que foi sintetizada artificialmente pelo químico alemão FredrichWohler em 1928, a partir do aquecimento de um composto inorgânico, o cianeto de amônio (Paixão; Pereira, 2011). Apesar de se apresentar como uma "forte evidência contra o argumento dos vitalistas de distinguir as substâncias vivas das não vivas" (Nascimento Júnior, 2010), não devemos enxergar esse episódio de forma ingênua e aclamá-lo isoladamente como a derrocada do vitalismo, pois uma concepção é marcada por vários pressupostos e sua superação envolve a reelaboração das diferentes ideias que a compõe.

Esse embate, entre fisicalistas e vitalistas, expõe as fragilidades das explicações vitalistas, mas também alicerça uma tentativa de padronização de abordagem dos fenômenos. Essas discussões são importantes na medida em que trazem facetas diferentes no que se refere à especificidade dos objetos de estudo de cada área de conhecimento e à diversidade de formas de captar cada realidade.

Chalmers (1993) afirma que muitas áreas de estudo buscaram e buscam ainda incluir aspectos do método empírico na tentativa de adquirir certa credibilidade e status de "ciência". Mas, para Mayr (2008), essa visão de método ideal não condiz com a complexidade do mundo vivo, sendo a abordagem funcionalista insuficiente para tal entendimento.

Segundo Ramos (2010), o pensamento científico biológico sofreu os reflexos do embate entre as ideias mecanicistas físico-químicas e vitalistas no século XIX e no início do XX. Essa convivência entre visões diferentes de seus respectivos objetos não é uma particularidade do campo biológico, pois a estruturação dos conhecimentos em diversas áreas, inclusive na 
física, também experimenta a proposta de abordagem sistemática de seus conceitos. Temos exemplos dessa abordagem nos campos das ciências ditas "exatas" na constatação de que fenômenos envolvendo eletromagnetismo e conservação da energia, durante o século XIX, não se enquadravam no paradigma newtoniano vigente. Havia entre os estudiosos a necessidade de explicar tais fatos considerando-se "algo mais", não expresso até então. É nessa explicação que a Naturphilosophie, programa filosófico associado ao movimento romântico alemão do século XIX, parece oferecer novos caminhos para entender as ciências (Silva; Silva, 2017, p.687).

As autoras ainda esclarecem que esse "algo mais" era identificado pelos adeptos dessa concepção filosófica, inclusive o seu precursor Friedrich von Schelling (1775-1854), como um princípio integrador de fenômenos naturais, "por meio dos processos de transformação e conversão" (Silva; Silva, 2017, p.687). Essa visão de mundo "se tornou o foco irradiador da crítica, no século XIX, à visão racionalista do cosmos e do homem que animava os filósofos" (Souza, 2010, p. 32), que tomou corpo em discussões relacionadas a todas as ciências e aparece na construção de conhecimentos da química, física e biologia (Silva; Silva, 2017).

Portanto, a coexistência de diferentes concepções dos fenômenos naturais marca a construção do pensamento biológico, que se estrutura em bases empíricas e históricas (Nascimento Júnior; Souza, 2016). O processo de entendimento da realidade é mediado por diferentes formas de apreensão de elementos dos fenômenos que a compõem. Nesse sentido, as diferentes formas de interpretação estão vinculadas a fatores históricos e culturais que marcam cada período e direcionam a (re)construção de conhecimentos.

Nascimento Júnior (2010), aponta as marcas e a importância das bases empíricas e históricas no século XIX, ao dizer que o desenvolvimento da biologia partiu, em especial, de duas diferentes visões de mundo: a natureza vista como processo em constante transformação (de Hegel) e a natureza como mecanismo (de Descartes e Newton). "A primeira subsidiou o pensamento evolutivo e, mais tarde, o ecológico e o biogeográfico. A segunda sustentou a ideia de constituição estrutural e funcional do organismo. É importante ressaltar que estas visões se expressaram de diferentes formas e mesmo existiram lado a lado" (Nascimento Júnior, 2010, p. 123)

O autor enfatiza que a biologia deve ser enxergada em sua dualidade complementar: de um lado a visão mecânica de Descartes apresentada no estudo das estruturas e funções dos componentes da matéria viva, do outro lado, Hegel fundamentando a visão histórica das transformações, adaptações e combinações, presente na diversificação e na interdependência entre seres vivos e ambiente. A história do pensamento biológico, nesse contexto, seria resultado da reelaboração de ideias dentro dessas perspectivas e a proposta de um olhar direcionado somente por uma dessas bases não contemplaria a tentativa de compreensão da complexidade do fenômeno vida, objetivo da biologia enquanto ciência. Na essência das ideias que predominam no século XXI, a complexidade do mundo vivo não pode ser resumida simplesmente ao estudo reducionista, objetivo e fragmentado das ideias mecanicistas (Capra; Luisi, 2014), e não é alcançada pela proposta mística vitalista. A viabilidade de uma visão sistêmica dos conhecimentos biológicos ganha destaque nessas discussões, ou seja, a visão organicista se estrutura nesse cenário de olhares concomitantes. 


\section{Para além do mecanicismo: o organicismo}

Bazzanella (2013) destaca o século XIX como um período de mudanças decisivas na visão do objeto vida, pois a articulação com princípios físicos e químicos favoreceu um novo olhar para o objeto de investigação da biologia. Esse movimento toma forma em uma nova proposta de compreensão do atributo vida, o organicismo (Capra; Luisi, 2014). Esses autores apontam que princípios mecanicistas foram primordiais para o desenvolvimento da teoria celular, da embriologia e da microbiologia, pois os instrumentos e as técnicas mecanicistas conseguiram elucidar aspectos básicos para a fundamentação desses conhecimentos.

O desenvolvimento dos conhecimentos biológicos revela uma dinâmica intrínseca aos processos vitais, que não é alcançada por uma visão reducionista, pois necessita de uma abordagem de atributos relacionados ao todo, ou seja, em um nível de complexidade que pode não decorrer diretamente de suas partes, mas da interação entre elas (Mayr, 1998). Fleck (2010) argumenta que as diferentes abordagens de um fato científico denunciam seu caráter provisório, pois advém de "uma relação de conceitos conforme o Estilo de Pensamento, que, embora possa ser investigável por meio dos pontos de vista históricos e da psicologia individual e coletiva, nunca poderá ser simplesmente construída, em sua totalidade, por meio desses pontos de vista" (Fleck, 2010, p. 132).

Sendo assim, o autor reconhece a existência de remodelações profundas na evolução histórica dos conhecimentos científicos, direcionadas por elementos sociais e lógicos. Além disso, dentro da concepção realista crítica de Fleck, a construção do conhecimento científico é entendida no âmbito da coexistência de ideias convergentes e divergentes que estruturam a elaboração do fato científico e atribuem a ele um caráter social, lógico, não linear e provisório, e isso pode ser entendido quando o autor afirma que,

[...] do ponto de vista da psicologia coletiva, [...] após os primeiros trabalhos de Wassermann sobre a sorologia da sífilis, havia muitos verificadores que procederam à "elaboração técnica".O alcançar de um resultado positivo, contudo, e seu conteúdo objetivo inicialmente não se explica por elementos da história evolutiva. Esses verificadores testaram muitas combinações, mas nem todas foram aprovadas da mesma maneira: somente uma delas tinha que ser avaliada como sendo a melhor, ou, pelo menos, somente algumas tinham que ser consideradas boas. Não há como reconstruir qual desses elementos chegou a sê-lo (Fleck, 2010, p. 127).

Considerando a necessidade de compreensão da coexistência de diferentes perspectivas e a não linearidade do desenvolvimento do pensamento científico, as principais ideias de cada corrente de pensamento biológico foram organizadas no Quadro 1. 
Quadro 1: Comparação entre as diferentes abordagens na compreensão do mundo vivo

\begin{tabular}{|c|c|c|c|}
\hline Abordagem & $\begin{array}{l}\text { Período de } \\
\text { prevalência }\end{array}$ & Principais ideias & Principais representantes \\
\hline Vitalista & $\begin{array}{l}\text { Século V a.C. } \\
\text { até século XIX }\end{array}$ & $\begin{array}{l}\text { As bases da corrente vitalista provêm das ideias } \\
\text { que circulavam na Grécia Antiga. } \\
\text { Concepção metafísica que cogita a existência de } \\
\text { um princípio irredutível (força vital) ao domínio } \\
\text { físico-químico para explicar os fenômenos vitais. } \\
\text { A força vital é interpretada como uma } \\
\text { característica inerente aos organismos vivos } \\
\text { e difere de todas as outras forças encontradas } \\
\text { fora das coisas vivas. } \\
\text { Alternativa à teoria reducionista da vida como } \\
\text { máquina. }\end{array}$ & $\begin{array}{l}\text { Hipócrates, Aristóteles, } \\
\text { Hans Adolf Eduard Driesch, } \\
\text { Constantin von Monakow, } \\
\text { Jan Baptista van Helmont, } \\
\text { Paul-Joseph Barthez, Johann } \\
\text { Friedrich Blumenbach, } \\
\text { Marie François Xavier Bichat, } \\
\text { Carl von Linné, } \\
\text { Claude Bernard e outros. }\end{array}$ \\
\hline Mecanicista & $\begin{array}{l}\text { Do século } \\
\text { XVII ao século } \\
\text { XIX }\end{array}$ & $\begin{array}{l}\text { A possibilidade de descrever os fenômenos que } \\
\text { ocorrem em um organismo em termos físicos. } \\
\text { O fenômeno vital é resultado de uma infinidade } \\
\text { de forças e de formas hierarquizadas. } \\
\text { Todos os fenômenos se explicam pela } \\
\text { causalidade mecânica ou em analogia à } \\
\text { causalidade mecânica. } \\
\text { Reelaboração da ideia organismo-máquina com a } \\
\text { contribuição dos processos químicos e elétricos. } \\
\text { As explicações mecanicistas opõem-se as expli- } \\
\text { cações vitalistas ao refutar a ideia de força vital } \\
\text { e ainda considerá-la como apelação ao místico. } \\
\text { Desenvolvimento da teoria celular despontou em } \\
\text { relação a funcionalidade do organismo e marcou } \\
\text { a limitação da teoria reducionista para explicar as } \\
\text { atividades integrativas dessa estrutura. }\end{array}$ & $\begin{array}{l}\text { Antonie Lavoisier, Giovanni } \\
\text { Borelli, Luigi Galvani, } \\
\text { Robert Hooke, Robert } \\
\text { Virchow, Willian Harvey } \\
\text { e outros. }\end{array}$ \\
\hline Organicista & $\begin{array}{l}\text { Do século } \\
\text { XIX aos dias } \\
\text { atuais }\end{array}$ & $\begin{array}{l}\text { A teoria evolucionista de Darwin ampara uma } \\
\text { visão holística e sistêmica do mundo vivo. } \\
\text { A proposta holista do organicismo se diferencia } \\
\text { da proposta vitalista ao ter uma abordagem } \\
\text { materialista. } \\
\text { Ênfase no todo, isto é, na integração. } \\
\text { Redução explicativa é malsucedida ao não } \\
\text { considerar que o "todo pode ser maior que } \\
\text { a soma das partes". }\end{array}$ & $\begin{array}{l}\text { Lloyd Morgan, Jan Smuts, } \\
\text { John Scott Haldane, David } \\
\text { Hull, Hans Christian Orsted, } \\
\text { Wimsatt, Beatty, Friedrich } \\
\text { Wilhelm Schelling, Hermann } \\
\text { Von Helmholtz, François } \\
\text { Jacob e outros. }\end{array}$ \\
\hline
\end{tabular}

Fonte: Adaptado de Simão (2018).

Percebemos, nesse quadro, que a ideia de "força vital" foi usada como um escape para questões, até então, nebulosas sobre as particularidades do objeto vida, e ainda a inadequação do modelo mecanicista para o entendimento dos sistemas vivos complexos, e, em particular, da interação entre informação historicamente adquirida e as respostas desses programas genéticos sobre o mundo físico. Os fenômenos vitais têm um objetivo mais amplo do que os fenômenos relativamente simples de que tratam a física e a química (Mayr, 1998, p. 71). De acordo com esse autor, o pensamento mecanicista ainda está presente na biologia experimental, que se ocupa especialmente da descrição e da funcionalidade de processos em níveis celular e moleculares. 
Sendo assim, percebemos que essa abordagem assume um papel importante, mas não exclusivo, na interpretação do fenômeno vida, ao esclarecer aspectos relevantes para uma visão integrada do mundo vivo. Em outros termos, ao considerá-la, assume-se que a percepção e o entendimento do fenômeno vida exigem a associação de diferentes abordagens. Ainda pensando nos aspectos complexos dessa interdependência,

Buffon, um estudioso da biologia, afirmava que o conhecimento biológico tinha uma estrutura peculiar. Em função dessa estrutura, não pode ser dirigido exclusivamente pelas leis da matemática, mas deve fundamentalmente buscar seguir o curso histórico dos fenômenos. Assim, nas ciências biológicas, deve-se adotar o procedimento de busca "arqueológica" em substituição ao método de conceitos lógico-matemáticos que tenderia, na biologia, a produzir exclusivamente uma classificação dos indivíduos em gêneros e espécies. Há de se substituir a definição pela descrição, o gênero pelo indivíduo, substituição que resultaria na compreensão das transformações ocorridas no tempo; daí a ênfase na descrição e na investigação histórica (Andery et al., 2000, p. 339).

Temos exemplo dessas limitações reducionistas quando tentamos aplicar apenas ideias fisicalistas para explicar o princípio da neuroplasticidade, que é a capacidade do sistema nervoso "modificar o seu funcionamento e de se reorganizar através de alterações ambientais ou de lesão" (Bastos; Alves, 2013, p. 51). Considerando a premissa de conhecer as partes para entender o todo, amparada pela perspectiva mecanicista, a perda de uma das partes inviabilizaria o funcionamento do todo. No entanto, esse fato biológico ilustra a possibilidade reorganização das partes e o restabelecimento das atividades neurais. Isso mostra que os sistemas vivos devem ser encarados, também, como totalidades integradas, que envolvem relações de organização das partes em um mesmo sistema (Maturana; Varela, 1997).

Para Capra e Luisi (2014), esse particularismo do sistema vivo evidencia a sua emergência e "precisa ser considerado juntamente com o da auto-organização. A palavra 'emergência' refere-se ao surgimento de novas propriedades da estrutura organizada, novas no sentido de que não são estão presentes nas partes ou nos componentes" (Capra; Luisi, 2014, p. 187).

Mayr (1998) afirma que o abandono das ideias vitalistas e a limitação reducionista do mecanicismo abriram um precedente para a retomada da visão integrada do mundo vivo, pré-ideias que já circulavam entre filósofos da Grécia Antiga, e sinaliza a instauração de um novo modelo explicativo que,

[...] aceitava que os processos no nível molecular poderiam ser explicados exaustivamente por mecanismos físico-químicos, mas que esses mecanismos desempenhavam um papel cada vez menor, se não desprezível, em níveis de integração mais altos. Eles são substituídos pelas características emergentes dos sistemas organizados. As características únicas dos organismos vivos não se devem à sua composição, e sim à sua organização. Esse modo de pensar é hoje comumente chamado de organicismo. Ele enfatiza em particular as características dos sistemas ordenados altamente complexos e a natureza histórica dos programas genéticos que evoluíram nos organismos (Mayr, 1998, p. 38).

Apesar de suas limitações, o pensamento clássico, disjuntor e reducionista, foi responsável pelo grande avanço das ciências naturais no século $X X$, pois possibilitou o entendimento de fenômenos inimagináveis, que são muito importantes para compreensão do mundo real 
(Hobsbawm, 2015). Hempel (1981) cita como exemplo dessa contribuição a caracterização molecular de substâncias como a penicilina, a testosterona e o colesterol para o desenvolvimento de conceitos biológicos, mas deixa claro que isso não permite uma interpretação dos fenômenos biológicos em aspectos físico-químicos.

No desenvolvimento do pensamento biológico, esse período (contemporaneidade) marca a reestruturação da biologia evolutiva (Futuyma, 2002a). Mayr (2005) afirma que os dois ramos da biologia evolutiva, o funcional e o histórico, se complementam na abordagem do objeto vida. O autor ressalta que a interação entre os dois campos evidencia diferenças na abordagem do objeto e nas discussões mais frequentes.

\footnotetext{
Com certeza, em ambos os campos se fazem perguntas do tipo "o quê?" para obter os fatos necessários para análise. A questão mais usual em biologia funcional, porém, é "como?"; em biologia evolucionista, "por quê?". Tal diferenciação não é completa porque em biologia evolucionista, ocasionalmente, também se fazem perguntas do tipo "como?" - por exemplo: como as espécies se multiplicam? No entanto, como veremos, para obter suas respostas, particularmente em casos nos quais experimentos não são apropriados, a biologia evolucionista desenvolveu sua própria metodologia, a das narrativas históricas (cenários hipotéticos) (Mayr, 2005, p. 40).
}

O desenvolvimento da biologia evolutiva representa um passo fundamental para a compreensão e a manipulação do mundo vivo. O delinear do modelo explicativo do processo de diversidade biológica garante a autonomia científica da biologia (Mayr, 2005). Apesar de esses avanços representarem um importante passo para a compreensão do fenômeno vida, eles despertam a necessidade de estudos aprofundados sobre as implicações dessas técnicas e ainda um exaustivo debate, considerando também os limites éticos de tais interferências (Futuyma, 2002a). Esse debate não deve ser negligenciado no âmbito do ensino dos temas biológicos.

\section{Considerações finais: uma breve descrição dos estilos de pensamento biológico}

Como já nos referimos ao desenvolvimento do pensamento biológico nos subtópicos anteriores, nos limitaremos a uma breve descrição das particularidades desses estilos. Para Fleck (2010), o Estilo de Pensamento determina as ideias que serão desenvolvidas dentro de um Coletivo de Pensamento, pois é o estilo que direciona a reelaboração dessas ideias. Sendo assim, o conceito de vida foi direcionado pelo Estilo de Pensamento Biológico dominante, em cada período histórico, e colaborou para o pensamento biológico atual.

Em Bertoni (2012), encontramos uma proposta de compreensão dessa dinâmica, a partir dos modelos interpretativos do fenômeno vida, expostos nas Diretrizes Curriculares de Biologia do estado do Paraná. Essa proposta é alicerçada nas premissas da epistemologia de Fleck, ao considerar que as construções epistemológicas do fenômeno vida podem ser reconhecidas no desenvolvimento do pensamento biológico como Estilos de Pensamento Biológico. O autor identificou quatro estilos, a saber: o Estilo de Pensamento Biológico Descritivo (EPBD), o Estilo de Pensamento Biológico Mecanicista (EPBM), o Estilo de Pensamento Biológico Evolutivo (EPBE) e, finalmente, o Estilo de Pensamento Biológico da Manipulação Genética (EPBMG). 
Bertoni (2012) esclarece que o EPBD tem o ponto de instauração nas concepções aristotélicas e apresenta marcas de extensão até o século XVII. É caracterizado pela descrição dos seres vivos, fundamentada em formas de identificação propostas "por civilizações anteriores aos gregos, sob influência do pensamento mítico" (Bertoni, 2012, p. 101). As tentativas racionais de compreensão do fenômeno vida na Grécia Antiga colaboram para o delineamento do EPBD que

[...] é inicialmente marcado por uma visão holista da natureza e a crença na concepção animista de que o fenômeno vida é causado por espírito ou um "sopro vital", que se apropria da matéria, ou um princípio vital próprio do animal que possui em si mesmo (potência). Assim, o estilo descritivo expressa uma concepção holística de vida (Bertoni, 2012, p. 100).

Apesar de toda e qualquer classificação do mundo vivo ser passível de críticas, mesmo descontadas as controvérsias teórico-metodológicas mais gerais, e envolver alguma dose de arbitrariedade, o recurso a elas possui aspectos positivos, que compensam os seus já esperados problemas. São eles: a organização do debate, a permissão de comparações no tempo e no espaço, e, talvez o mais importante para a discussão ora realizada, a contribuição da incorporação de diferentes formas de tratar determinados fenômenos, inclusive o fenômeno vida. Nesse contexto descritivo, a abordagem do fenômeno vida é condicionada a aspectos classificatórios, mas imutabilidade e fixidez teológica também são marcas desse edifício do saber. Os determinantes dessa estrutura são ideias naturalistas aristotélicas que predominam até o século XVIII, quando as discussões e novas perspectivas apontaram as fragilidades e as inconsistências das bases desse pensamento (Bertoni, 2012). Segundo o autor, essas inconsistências estão relacionadas à nova forma de abordagem do real e a reflexos das interações sociais características do período.

Essas mudanças nas interações sociais vigoram na instauração e consolidação do EPBM. Assim, como aconteceu em outros campos de estudo, uma nova forma de conceber o real se desvincula da relação Deus/homem e reconhece na relação homem/natureza uma forma de compreensão da realidade que se distanciava das incertezas da contemplação e se ligava à busca de possíveis verdades (Andery et al., 2000). Os autores indicam as propostas metodológicas de Bacon, o empirismo, e de Descartes, o racionalismo, como as vias que despontaram nessa nova percepção de real. Esse caminho começa a ser traçado quando, ao explicar as causas dos fenômenos por causas mecânicas - o movimento dos átomos - Demócrito lançou as bases do materialismo mecanicista. Seus mais famosos seguidores foram Epicuro e Lucrécio.

Para Santos (2008), o mecanicismo se destaca ao levantar a bandeira de progresso no século XVIII, com uma conveniente campanha da burguesia em ascensão, sendo o ideário do conhecimento utilitário, ou seja, essa abordagem do real se apresentava distanciada da possibilidade de compreender profundamente o real e estava diretamente relacionada ao reconhecimento e à transformação da realidade em busca de atender os interesses de seus financiadores.

Segundo Bertoni e Luz (2011), a inserção dos pressupostos fisicalistas nas pesquisas biológicas ocorreu no campo médico, com a contribuição de William Harvey (1578-1657) para a anatomia e a fisiologia da circulação. Esse médico britânico levantou ideias que configuraram a transformação do EPBD, pois desenvolveu o estudo do sistema circulatório a partir de concepções de análise das funcionalidades das partes para a compreensão das funções integrativas. Dessa forma, apresenta-se uma concepção de vida fundamentada nas "forças mecânicas" (Bertoni; Luz, 2011, p. 35). 
A busca pela autonomia de um campo de estudo do mundo vivo figurava como o principal embate entre naturalistas e fisicalistas, mas uma das críticas a essa reivindicação era a falta de explicações cientificamente coerentes para a diversidade de seres vivos. A resposta a essas críticas surgiu na proposta de uma síntese integrativa dos conhecimentos biológicos já produzidos em um modelo explicativo para a diversidade dos seres vivos, a teoria da evolução da vida (Bertoni, 2012). Esse olhar diferenciado para o fenômeno vida alicerçou várias reelaborações de ideias e colaborou para o desenvolvimento do estudo da relação homem/natureza em novos campos.

No EPBE, a matéria e a natureza são percebidas numa interação que emerge também no todo, pois são considerados

[...] em vez da eternidade, a história; em vez do determinismo, a imprevisibilidade; em vez do mecanicismo, a interpenetração, a espontaneidade e a auto-organização; em vez da reversibilidade, a irreversibilidade e a evolução; em vez da ordem, a desordem; em vez da necessidade, a criatividade e o acidente. A teoria de Prigogine recupera inclusivamente conceitos aristotélicos, tais como os conceitos de potencialidade e virtualidade que a Revolução Científica do século XVI parecia ter atirado definitivamente para o lixo da história (Santos, 2008, p. 48).

A incorporação de elementos a serem utilizados como critérios de corte e que dialoguem com os fatores presentes e futuros dessa interação, como a tecnologia e a disseminação de informação, apresenta contribuições para o reconhecimento das particularidades desse campo científico em formação. Além disso, os esforços de superação e substituição de velhas dicotomias, como a queda de braço entre a subjetividade e a objetividade em busca de um pretenso ideal de cientificidade, por novas, como entre atividades mais intensivas em tecnologia e conhecimento versusatividades menos intensivas, são, além de louváveis, particularmente úteis e conectadas com o nosso tempo.

Nesse contexto de reconhecimento científico, o século XX pode ser considerado a consolidação da biologia, pois as ideias sobre o mecanismo evolutivo são reelaboradas e ampliadas com o desenvolvimento de conhecimentos relacionados à teoria celular e à genética molecular. Essas contribuições reestruturam o Estilo de Pensamento vigente e evidenciam a instauração do EPBMG que "ainda em processo de organização inicial, exige um novo modelo explicativo que demarca a condição do ser humano em compreender o fenômeno vida a partir da estrutura físico-química dos seres vivos, os mecanismos celulares, as consequentes alterações biológicas, e as novas relações e interações" (Bertoni; Luz, 2011, p. 43).

Nesse caso, vemos demarcada a relação homem/natureza numa perspectiva que ultrapassa a tentativa de explicar o real, pois já o faz para modificá-lo e mobilizá-lo em busca da possibilidade de controle do processo. Do ponto de vista da reelaboração das ideias do conceito de vida, nesse estilo se destacam as ideias relacionadas à possibilidade de intervenção e alteração do processo de evolução natural com finalidade produtiva. Segundo Bertoni e Luz (2011), as especificidades de cada estilo podem ser compreendidas de acordo com as características dispostas no Quadro 2. 
Quadro 2: Apresentação do conceito de vida a partir dos quatro estilos de pensamento biológico

\begin{tabular}{|c|c|c|c|c|}
\hline Estilo & Concepção de vida & Singularidade & Concepção abrangente & Conceito \\
\hline Descritivo & $\begin{array}{l}\text { Descritiva-indutiva, } \\
\text { holística, limitada ao } \\
\text { organismo }\end{array}$ & $\begin{array}{l}\text { Propriedade } \\
\text { essencial }\end{array}$ & $\begin{array}{l}\text { Princípio vital; } \\
\text { sopro vital (criação divina) }\end{array}$ & $\begin{array}{l}\text { Conceito } \\
\text { essencialista de } \\
\text { vida }\end{array}$ \\
\hline Mecanicista & $\begin{array}{l}\text { Analítico-explicativa, } \\
\text { mecanicista, } \\
\text { reducionista } \\
\text { ao funcionamento das } \\
\text { partes do organismo e } \\
\text { aos mecanismos físico- } \\
\text {-químicos celulares }\end{array}$ & $\begin{array}{l}\text { Propriedade } \\
\text { funcional }\end{array}$ & $\begin{array}{l}\text { Redução do fenômeno vida } \\
\text { às leis físicas e químicas }\end{array}$ & $\begin{array}{l}\text { Conceito } \\
\text { funcionalista de } \\
\text { vida }\end{array}$ \\
\hline Evolutivo & $\begin{array}{l}\text { Contextual, organicista } \\
\text { e complexa: } \\
\text { célula } \leftrightarrow \text { organismo } \leftrightarrow \\
\text { biosfera }\end{array}$ & $\begin{array}{l}\text { Propriedade } \\
\text { emergente }\end{array}$ & Integração & $\begin{array}{l}\text { Conceito } \\
\text { emergentista de } \\
\text { vida }\end{array}$ \\
\hline $\begin{array}{l}\text { Manipulação } \\
\text { genética }\end{array}$ & $\begin{array}{l}\text { Relacional (relações de } \\
\text { causalidade), } \\
\text { reducionista- } \\
\text { genecêntrica, } \\
\text { manipulação das } \\
\text { bases físico-químicas } \\
\text { da vida }\end{array}$ & $\begin{array}{l}\text { Propriedade } \\
\text { genética }\end{array}$ & $\begin{array}{l}\text { Intervenção e alteração } \\
\text { da evolução natural do } \\
\text { fenômeno vida }\end{array}$ & $\begin{array}{l}\text { Conceito relacional } \\
\text { de vida }\end{array}$ \\
\hline
\end{tabular}

Fonte: Simão (2018, p. 67) a partir das discussões de Bertoni e Luz (2011).

A organização do Quadro 2 é uma indicação dos estilos de pensamentos identificados na construção do objeto de estudo da biologia e não pode ser entendida como uma sobreposição de estilos, pois temos, em itens anteriores, a demarcação da coexistência de mais de um estilo em diferentes períodos. Essa identificação teórica pode contribuir para captar o entendimento sobre o desenvolvimento do pensamento biológico, importante para entender a biologia como ciência autônoma com características que superam aquelas nas quais se apoia a física.

A partir desse entendimento, é possível utilizar a construção do conceito de vida como uma valiosa estratégia para compreender o passado, segundo nossa visão de mundo, e o presente, mediante visões de mundo que contribuíram para o desenvolvimento do pensamento biológico. Assim, também se pode pensar em elementos pedagógicos para se discutir, por exemplo, no ensino de ciências/biologia, a construção e reelaboração de conceitos que, estruturados em um corpo teórico-metodológico, modificaram a forma de abordar e interpretar o objeto vida, integrando as discussões advindas da filosofia da biologia contemporânea na tentativa de compreender esse processo. 


\section{Referências bibliográficas}

ALFONSO-GOLDFARB, A. M. O que é história da ciência. São Paulo: Brasiliense, 1994.

ANDERY, M. A. et al. Para compreender a ciência: uma perspectiva histórica. $9^{a}$ ed. São Paulo: Educ, 2000.

ARISTÓTELES. Partes dos animais. Trad. de Ana Maria Lóio. Lisboa: Imprensa Nacional; Casa da Moeda, 2010. (Obras completas de Aristóteles, v. IV)

ARISTÓTELES. Sobre a alma. Trad. de Ana Maria Lóio. Lisboa: Imprensa Nacional; Casa da Moeda, 2010a. (Obras completas de Aristóteles, v. III)

BASTOS, L. S.; ALVES, M. P. As influências de Vygotsky e Luria à neurociência contemporânea e à compreensão do processo de aprendizagem. Revista Praxis. Volta Redonda, ano V, n. 10, p. 41-53, 2013. Disponível em: http://revistas.unifoa.edu.br/index.php/praxis/article/ view/580. Acesso em: 10 jan. 2018.

BAZZANELLA, S. L. A definição de vida partir de perspectivas da biologia e da física: organicismo mecanicista. In: Congresso Internacional Interdisciplinar em Sociais eHumanidades, 3. 2013, Belo Horizonte. Anais... Belo Horizonte: Instituto de estudos do Desenvolvimento Sustentável, 2013.

BERTONI, D. Gênese e desenvolvimento do conceito de vida. 2012. 247f. Tese (Doutorado em Educação) - Universidade Federal do Paraná, Curitiba, 2012.

BERTONI, D.; LUZ, A. A. Estilos do pensamento biológico sobre o fenômeno da vida. Revista Contexto e Educação. ljuí, v. 86, p. 23-49, 2011.

CANGUILHEM, G. Estudios de historia y de filosofía de lasciencias. Buenos Aires: Amorrortu, 2009.

CANGUILHEM, G. O conhecimento da vida. Rio de Janeiro: Forense Universitária, 2012.

CAPRA, F.; LUISI, P. L. A visão sistêmica da vida: uma concepção unificada e suas implicações filosóficas, políticas, sociais e econômicas. São Paulo: Cultrix, 2014.

CHALMERS, A. F. O que é a ciência afinal? São Paulo: Brasiliense, 1993.

COUTINHO, F. A. A construção de um perfil conceitual de vida. 2005. 201f. Tese (Doutorado em Educação) - Universidade Federal de Minas Gerais, Belo Horizonte, 2005.

FLECK, L. Gênese e desenvolvimento de um fato científico. Belo Horizonte: Fabrefactum, 2010.

FOUCAULT, M. As palavras e as coisas. 9a edição. São Paulo: Martins Fontes, 2000.

FUTUYMA, D. J. Biologia evolutiva. Ribeirão Preto: Funpec-RP, 2002a.

FUTUYMA, D. J. Evolução, ciência e sociedade. Ribeirão Preto: Sociedade Brasileira de Genética, 2000b.

HEMPEL, C. Filosofia da ciência natural. Rio de Janeiro: Zahar, 1981.

HOBSBAWM, E. Feiticeiros e aprendizes: as ciências naturais. In:HOBSBAWM, E. A Era dos Extremos: o breve século XX, 1914-1991. São Paulo: Companhia das Letras, 2015. p. 504-536.

LOPES, J. L. A imagem física do mundo: de Parmênides a Einstein. Estudos Avançados. São Paulo, v. 12, n. 5, p. 91-121, 1991. 
MARE, R.A. A concepção da teoria evolutiva desde os gregos. Porto Alegre: EdiPUC-RS, 2002.

MATURANA, H.; VARELA, F. De máquinas e seres vivos: autopoiese: a organização do vivo. $3^{\mathrm{a}}$ ed. Porto Alegre: Artes Médicas, 1997.

MAYR, E. O desenvolvimento do pensamento biológico. Brasília: Editora UnB, 1998.

MAYR, E. Biologia, ciência única: reflexões sobre a autonomia de uma disciplina científica. São Paulo: Companhia das Letras, 2005.

MAYR, E. Isto é biologia: a ciência do mundo vivo. São Paulo: Companhia das Letras, 2008.

NASCIMENTO JÚNIOR, A. F. Construção de estatutos de ciência para a biologia numa perspectiva histórico-filosófica: uma abordagem estruturante para seu ensino. 2010. 437f. Tese (Doutorado em Educação para a Ciência) - Faculdade de Ciências, Universidade Estadual Paulista, Bauru, 2010.

NASCIMENTO JÚNIOR, A. F.; SOUZA, D. C. A busca das ideias estruturantes da biologia na história do estudo dos seres vivos no século XIX. Theoria: Revista Eletrônica de Filosofia. Pouso Alegre, v. VIII, p. 58-88, 2016. Disponível em: https://www.theoria.com.br/ edicao19/04012016RT.pdf. Acesso em: 10 jan. 2018.

OPARIN, A. A origem da vida. $9^{a}$ ed. São Paulo: Global, 1989.

PAIXÃO, F.; PEREIRA, M. Superação do vitalismo e o imparável desenvolvimento da síntese orgânica. Química: Boletim da Sociedade Portuguesa de Química. Lisboa, v. 120, p. 39-41, jan.-mar., 2011. Disponível em: http://hdl.handle.net/10400.11/1367. Acesso em: 10 jan. 2018.

RAMOS, M. deC. O ser vivo. São Paulo: Martins Fontes, 2010.

ROSA, C. A. P. História da ciência: a ciência moderna. $2^{\mathrm{a}}$ ed. Brasília: Funag, 2012.

SANTOS, B.S. Um discurso sobre as ciências. $7^{\mathrm{a}}$ ed. São Paulo: Cortez, 2008.

SILVA, A. P. B.; SILVA, J. A. A influência da "Naturphilosophie" nas ciências do século XIX: eletromagnetismo e energia. História, Ciências, Saúde, Manguinhos, v. 24, n.3, p. 687- 705, 2017.

SIMÃO, M. M. Abordagem do conceito de vida no ensino de ciências e biologia: uma análise de artigos científicos brasileiros a partir da epistemologia de Fleck. Dissertação (Mestrado em Educação em Ciências e Matemática) - Universidade Federal de Goiânia, Goiânia, 2018.

SOUZA, M. C. S. A "Naturphilosophie" como concepção de mundo do romantismo alemão. Aisthe. Rio de Janeiro, v. 4, n. 5, p. 31-47, 2010. Disponível em: https://revistas.ufrj.br/index. php/Aisthe/article/view/11888. Acesso em: 10 jan. 2018.

Recebido em abril de 2021

Aceito em agosto de 2021 